\title{
CUSTOMER OR COMPLEMENTOR? Intercarrier Compensation with Two-Sided Benefits
}

31 July 2006

\author{
Benjamin E. Hermalin \\ and \\ Michael L. Katz*
}

We are grateful to Bruno Jullien, Patrick Rey, and participants at the 2004 IOfest and the 2005 European Summer Symposium in Economic Theory for helpful comments and suggestions.

* Haas School of Business

University of California, Berkeley

Berkeley, CA 94720-1900 


\begin{abstract}
Both senders and receivers of telecommunications messages derive benefits, creating the possibility of externalities. We explore whether intercarrier compensation (i.e., access charges) can induce carriers to internalize these external effects. In important settings, access charges are irrelevant. Where they are relevant, access charges can induce an efficient ratio of off-net send and receive prices-taking their sum as given-but cannot induce the correct sum. The latter requires a mechanism for cross-carrier internalization, such as repeat play or pricing policies contingent on one another. Lastly, non-zero access charges can be efficient even in highly symmetrical situations.
\end{abstract}

\title{
Key Words
}

Access charge, intercarrier compensation, interconnection, two-sided markets. 


\section{INTRODUCTION}

The benefits from subscribing to a communications network derive from being able to exchange messages with other parties. The interconnection of distinct networks allows users to communicate with a large community of users without the need for carriers to duplicate one and others' networks. Interconnection can thus significantly affect efficiency and market structure. Consequently, interconnection rules, particularly those concerning intercarrier compensation, are one of the most important areas of public policy concerning telecommunications markets. ${ }^{1}$

Consumption of communications services (e.g., talking on the phone, exchanging emails, sharing files, or holding a video conference) generally involves a sender and receiver, both of whom take actions, bear costs, and derive benefits. ${ }^{2}$ Until very recently, almost all theoretical work on interconnection pricing ignored the benefits enjoyed by the receiving party. ${ }^{3}$ This treatment typically was justified by assuming either that the receiving party enjoys no benefits from a message exchange or that the effects between two parties are internalized. The first assumption clearly is unrealistic. Were it correct, we would never answer the telephone or read our e-mail. The second assumption is applicable only to situations in which either the two parties are altruistic with respect to one another or have a repeated relationship. ${ }^{4}$

1 It is also one of the most contentious. For a discussion of some of the policy issues, see Federal Communications Commission (2005).

2 The fact that multiple parties consume a single message gives rise to external effects. See Hermalin and Katz (2001b), Laffont and Tirole (2000), and Taylor (1994, Chapter 9) for surveys of telecommunications externalities.

3 Leading analyses without receiver benefits include Armstrong (1998) and Laffont et al. (1998a and b).

$4 \quad$ Loosely speaking, Willig (1979, pages 124-25) shows that, if sending a message triggers a set number of incoming messages, then receiver benefits will be internalized in the demand for sending messages. Hermalin and Katz (2001b, §3.5) develop a simple game-theoretic model in which users can (partially) internalize external benefits by engaging in tit-for-tat message initiation. 
Recognition that both sender and receiver enjoy benefits has important implications for efficient pricing to end users. ${ }^{5}$ These, in turn, have further implications for efficient pricing of interconnection. In the absence of receiver benefits, the sender can be viewed as the "cost causer.” This view suggests that the receiver's network should recover its message costs from the sender, either directly by billing the sender, or indirectly by billing the sender's carrier (i.e., by levying an access charge). This view forms the basis for telecommunications policy in the United States. According to the Federal Communications Commission, "under the existing regimes, the calling party's carrier, whether [a local, long distance, or wireless service] provider, compensates the called party's carrier for terminating the call.”6

In the presence of receiver benefits, this rationale for access charges makes little sense. One could just as well assert that the receiver causes the costs by accepting the message. Even the label "access charge" is misleading. Instead of viewing the originating carrier as a customer purchasing terminating access services, one could just as well think of the terminating carrier as purchasing origination services. It is better to think of each carrier as providing a service that is complementary to the other.

Our analysis of intercarrier compensation in the presence of two-sided benefits proceeds as follows. We first characterize the socially optimal end-user prices and extend the literature (specifically, Hermalin and Katz, 2004, and Laffont et al., 2003) by allowing for hookup fees and meaningful end-user subscription decisions. Because prices can play a role in internalizing external effects across the two parties to a message exchange, it is inefficient to have one party

$5 \quad$ For a discussion of the earlier literature on retail pricing in the presence of two-sided benefits, see Hermalin and Katz (2004) and references therein.

$6 \quad$ Federal Communications Commission (2005, \ 17, foot note omitted). 
bear the full marginal costs of exchanging a message and, indeed, it is typically inefficient for the two parties exchanging a message collectively to bear the full marginal costs.

We then explore the relationship between access charges and equilibrium end-user prices. When a sender and receiver are on the same network, the network operator may find it profitable to set prices that internalize what would otherwise be consumption externalities across the two end users. The network will do so when it is able to capture some of the increased consumption benefits in the form of higher network subscription fees. When the sender and receiver are on different networks, however, these incentives do not arise. Intuitively, efficient pricing entails setting price below cost to at least one end user in order to increase the flow of messages from which the other end user will derive benefits. In our model, if each network can collect revenues only from its own subscribers and there is no other coordination or internalization mechanism, then there is no way for a network to benefit from internalizing externalities. ${ }^{7}$

We first consider the interconnection of perfectly differentiated networks. We show that access charges cannot induce a carrier to set the sum of its sending and receiving prices for messages exchanged with another network (“off-net calls") below marginal cost, which would be required for efficiency. Indeed, the access charge level has no effect on the sum of the prices. One might suspect that access charges would be irrelevant in this setting. However, as we show, access charges still can have a role to play in achieving the optimal ratio of end-user prices for sending and receiving messages across networks. Moreover, even in what appear to be very symmetrical situations, a non-zero access charge (either positive or negative) may be efficient.

7 In a more general model, it is conceivable that a carrier's subsidizing subscribers to a rival carrier would so increase the number of end users connected to the overall network that the value of the subsidizing carrier's own service would rise by enough to make the subsidy profitable. 
We next examine competition between undifferentiated networks. Here, intercarrier compensation in the form of simple access charges cannot solve the problem of cross-carrier externalities except in the degenerate sense of pushing the market to an equilibrium in which all users are on a single network. Given the different degrees to which on- and off-net prices internalize the two-sided benefits of message exchange, one might suspect that a rule requiring carriers to charge the same prices for on- and off-net calls would improve the equilibrium outcome. We demonstrate that it need not. We first establish that, in any symmetric equilibrium with undifferentiated carriers, the access charge level cannot induce efficient prices because it cannot affect the sum of the sending and receiving prices. Moreover, we show that the rule could harm efficiency. The reason is that high off-net prices can be one means of achieving internalization by driving end users to a single network. A non-discrimination rule can make it impossible for a carrier to offer efficient on-net prices without inviting a form of free riding by a competing carrier and its subscribers.

We also examine two mechanisms through which carriers may coordinate their off-net pricing and thus set prices that internalize external effects when two end users exchange a message but subscribe to different networks: repeat play and strategic delegation, where the latter allows the use of interdependent pricing policies. In each case, we find that access charges are—in an important sense-irrelevant. ${ }^{8}$

The remainder of the paper is organized as follows. Section II describes the baseline model. Section III characterizes the socially optimal end-user prices. Section IV examines perfectly differentiated, monopoly networks. Sections V and VI then characterize equilibrium in 
a duopoly market with undifferentiated carriers under various assumptions about the degree of pricing flexibility. Section VII considers two possible mechanisms for cross-carrier internalization. Section VIII describes the relationship between the present paper and previous work. The paper closes with a short summary.

\section{A MODEL}

We model communication between different end users as a message exchange. A message might be a telephone call, a paging message, an SMS message, a data file, or an e-mail. One party initiates the communication (e.g., places a phone call) and the other party accepts it (e.g., answers the phone). We refer to the initiator as the sender and the acceptor as the receiver.

When message exchange generates benefits and costs for both parties, there are important differences between situations in which either party can initiate a message exchange ("two-way calling”) and those in which only one party can do so (“one-way calling”). Our analysis, like the rest of the literature on intercarrier compensation with two-sided benefits, is restricted to oneway calling. ${ }^{9}$

One-way calling has several interpretations. One is that message origination is literally one-sided. Many telecommunications technologies, such as paging and pay phones are inherently one-way technologies. Other technologies are two way, but in many instances only one of the two parties knows there is value in communicating. For instance, $A$ could wish to announce some news to $B$. Alternatively, $A$ could be a consumer calling a pizza parlor, $B$, to

$8 \quad$ Under the assumption that receivers enjoy no benefits of message exchange Dessein (2003), Hahn (2004), and Laffont et al. (1998b) obtained similar results for very different reasons. Dessein and Hahn also assumed that there is no discrimination between on- and off-network calling.

$9 \quad$ As shown in Hermalin and Katz (2004), two-way calling can give rise to a waiting game when the send price is greater than the receive price. Strategic waiting does not arise in a one-way calling model. 
order a pie. Or, $A$ could be an end user establishing a dial-up connection with her Internet service provider, $B$. In such situations, it is reasonable to view only one of the two parties as the potential message initiator. Other situations, in which the parties both know there's a value to communicating and it is technically feasible for either party to initiate a message exchange, are two-way calling situations. ${ }^{10}$

There are two networks, 1 and 2. A network incurs cost $c$ to originate or terminate a message, and the incremental cost of a message exchange is thus $2 c$ regardless of the identities of the originating and terminating networks. Network $i$ offers a multipart tariff with a fixed hookup fee, $h_{i}$, and a set of traffic-sensitive charges. Let $p_{i j}$ denote the retail price charged to a user on network $i$ who sends a message to a user on network $j$. We refer to $p_{i j}$ as the on-net send price when $i=j$ and the off-net send price when $i \neq j$. Define the receive prices, $r_{i j}$, in the obvious manner. Henceforth, it is to be understood that $i \neq j$, so that, for example, $p_{i i}$ and $p_{i j}$ denote the on-net and off-net send prices, respectively, charged by network $i$.

There is a continuum of identical end users of measure 2. Each user is motivated only by his or her private net benefits, and income effects are assumed to be zero. A user subscribes to at most one carrier and exchanges either one message or none. ${ }^{11}$ Any given user has a $1 / 2$ chance of being a sender and a $1 / 2$ chance of being a receiver. The uncertainty is resolved after carrier

An alternative interpretation of the distinction between one-way and two-way calling models is the following. For cheaply priced messages, strategic waiting of the type identified in footnote 9 may be implausible even with a two-way technology, and the situation can be approximated by one-way calling model in which a party sends message whenever her expected value of message exchanges exceeds the price she must pay.

11 One could also allow for a single consumer to exchange multiple messages. In that case, $D(\cdot)$ below could be interpreted as a demand curve for multiple messages in a situation where everyone might exchange a message with anyone else and the expected values of message exchange were independent across potential exchange partners. The mapping between the number of subscribers and the number of messages would, of course, be somewhat different. 
subscription decisions have been made. Let $\psi(\omega)$ denote the density for the expected value of a message sent or received, $\omega .{ }^{12}$ Without loss of generality, normalize message values so that the support of $\psi(\cdot)$ has an infimum of 0 . To avoid trivial cases, we assume throughout that the supremum of the support of $\psi(\cdot)$ exceeds $c$ and that the mean value of $\omega$ is less than $2 c$.

Define $D(q) \equiv \int_{q}^{\infty} \psi(\omega) d \omega . D(q)$ is the probability that a user's expected value of a message exchange exceeds $q$. Given our assumptions about the mass and types of users, $D(p)$ is the expected demand for message origination at price $p$ and $D(r)$ is the expected demand for message reception at price $r$. Next, define $S(q) \equiv \int_{q}^{\infty}(\omega-q) \psi(\omega) d \omega . S(q)$ is the expected surplus of a message (sent or received) for which the user pays $q$. Lastly, define $M(q)$ as the mean of $\omega$ conditional on $\omega \geq q$ and observe that:

$$
M(q)=\frac{S(q)}{D(q)}+q
$$

The timing of the game is as follows.

- $\quad$ The access charge, $a$, that carrier $i$ must pay to carrier $j$ for each message that originates on $i$ and terminates on $j$ is specified. We assume that the access charge is the same for both carriers (i.e., it is a symmetric reciprocal compensation scheme). We analyze the choice of access charge made by a total-surplus-maximizing regulator and by the carriers ante; that is, sender and receiver could each learn, after message exchange, that the actual value of a message was different than they expected when they chose to send and receive the message. See Hermalin and Katz (2004) for a discussion. In the context of the present paper, the distinction between ex ante and ex post values is unimportant, and one is free to interpret $\omega$ as the actual value. 
themselves. We observe that, a priori, the socially optimal access charge could be negative or positive.

- Carriers simultaneously choose their pricing policies. We examine situations in which carriers have full pricing flexibility and each carrier chooses a quintuple of prices. We also consider more restrictive pricing strategies.

- End users simultaneously choose a carrier to which to subscribe, if any.

- Each end user learns whether he or she is a sender or receiver and then chooses whether to participate in a message exchange.

Lastly, our solution concept is perfect Bayesian equilibrium. When on- and off-net prices differ, a consumer must form beliefs about the carrier choices of other consumers. Throughout, we impose the following minimal rationality constraint on these beliefs: a consumer cannot believe that a network will fail to attract customers if being the only customer on that network would yield a higher surplus level than would playing the proposed equilibrium subscription strategy.

\section{OPTIMAL END-USER PRICES}

Although our focus is on inter-carrier pricing, the welfare consequences of interconnection charges in our model derive from their effects on the resulting retail prices. ${ }^{13}$ In this section, we characterize the socially optimal retail prices by extending Hermalin and Katz (2004) to settings in which carriers can charge positive hook-up fees and at the time the subscription decision is made an end user does not know whether he or she will be a sender or receiver. 
An end user who subscribes to network $i$ enjoys expected surplus

$$
\frac{1}{2}\left(\alpha_{i} D\left(p_{i i}\right) S\left(r_{i i}\right)+\left(1-\alpha_{i}\right) D\left(p_{j i}\right) S\left(r_{i j}\right)\right)+\frac{1}{2}\left(\alpha_{i} D\left(r_{i i}\right) S\left(p_{i i}\right)+\left(1-\alpha_{i}\right) D\left(r_{j i}\right) S\left(p_{i j}\right)\right)-h_{i},
$$

where $\alpha_{i}$ is the proportion of users who join network $i$. Efficient prices maximize total surplus,

$$
\begin{aligned}
\sum_{i=1}^{2}\left(\alpha_{i}^{2}(\right. & \left.D\left(p_{i i}\right) S\left(r_{i i}\right)+D\left(r_{i i}\right) S\left(p_{i i}\right)+\left(p_{i i}+r_{i i}-2 c\right) D\left(p_{i i}\right) D\left(r_{i i}\right)\right) \\
& \left.+\alpha_{i}\left(1-\alpha_{i}\right)\left(D\left(p_{i j}\right) S\left(r_{j i}\right)+D\left(r_{j i}\right) S\left(p_{i j}\right)+\left(p_{i j}+r_{j i}-2 c\right) D\left(p_{i j}\right) D\left(r_{j i}\right)\right)\right) .
\end{aligned}
$$

By assumption, $S(c)>0$, so shutting down both networks cannot be efficient. Setting the send or receive prices below 0 offers no efficiency gains, so we may take these prices as being bounded below by 0 .

Observe that maximizing total surplus can be divided into four independent maximization problems of the form

$$
\max S(p) D(r)+S(r) D(p)+(p+r-2 c) D(p) D(r) .
$$

The derivative with respect to the send price is

$$
D^{\prime}(p)\{S(r)+(p+r-2 c) D(r)\} .
$$

Because user surplus and demand are positive, the change in welfare due to a marginal change in the send price is negative if $p+r \geq 2 c$. Applying a similar logic to the choice of the receive price, it follows that any efficient price pair, say $\left(p^{*}, r^{*}\right)$, must satisfy $p^{*}+r^{*}<2 c{ }^{14}$ Intuitively, each end user's decision to participate in a message exchange generates positive expected surplus for the other party to the exchange and below-cost pricing serves to internalize this effect. Because efficient send and receive prices do not cover costs, optimal pricing subject see Hermalin and Katz (2006) and Valletti and Cambini (2005). 
to a carrier breakeven constraint entails a strictly positive hookup fee. End-user homogeneity implies that subscribers' individual rationality constraints will be satisfied by efficient pricing.

We can use equation (1) to rewrite the derivative with respect to the send price as

$$
D^{\prime}(p) D(r)\{M(r)+p-2 c\} .
$$

Given an $r$ for which $D(r)>0$, an interior solution for $p$ exists if and only if $M(r)-2 c \leq 0$ and a corner solution of $p=0$ exists if and only if $M(r)>2 c$. Intuitively, $p$ is the value of a marginal message to the sender who faces price $p$, and $M(r)$ is the expected gross benefit enjoyed by a receiver who accepts the message conditional on its value being greater than $r$. Hence, the firstorder condition indicates that, if it is an interior solution, $p$ must be set so that the expected gross consumption benefits of the marginal message, $p+M(r)$, are equal to the marginal cost, $2 c{ }^{15}$

Similar considerations apply to the choice of the receive price.

In the Appendix, we prove:

Proposition 1: Suppose that hook-up fees are feasible.

(i) If the hazard rate associated with $\psi(\cdot)$ is everywhere increasing, then there is a unique pair of prices that maximize total surplus and they satisfy $0<p^{*}=r^{*}<c{ }^{16}$

(ii) If the hazard rate is constant, then any prices such that $0 \leq p \leq 2 c-M(0)$ and $r=2 c-M(0)-p$ are socially optimal. ${ }^{17}$ the socially optimal prices of a monopolist that is not subject to a profitability constraint and that cannot charge a hookup fee. latter has a shape parameter greater than one. 
(iii) If the hazard rate is everywhere decreasing, then there are two socially optimal price pairs: one in which the send price equals 0 and one in which the receive price equals 0 . In each case, the complementary price equals $2 c-M(0)>0 .{ }^{18}$

For later use, let $V$ denote profit per subscriber gross of the hookup fee, the variable profit. Of particular importance is

$$
V^{*} \equiv \frac{1}{2}\left(p^{*}+r^{*}-2 c\right) D\left(p^{*}\right) D\left(r^{*}\right) \cdot \cdot^{19}
$$

Let $U$ denote the per-subscriber consumer surplus gross of the hookup fee, and define

$$
U^{*} \equiv \frac{1}{2}\left(D\left(p^{*}\right) S\left(r^{*}\right)+D\left(r^{*}\right) S\left(p^{*}\right)\right) .
$$

By construction, $V^{*}+U^{*} \geq V+U$ for any other vector of prices.

\section{MONOPOLY NETWORKS}

We next consider the market equilibrium when the two carriers choose their prices to maximize their profits and the carriers offer perfectly differentiated products. That is, each carrier has the loyalty of one half of the population of end users in that those end users will either subscribe to it or subscribe to no carrier. This situation can be thought of one in which the two carriers serve different locations and each is a local monopolist.

Because of network effects, consumers face a coordination problem and multiple equilibria can arise, depending on consumer expectations. In the case of monopoly networks,

In an insightful paper, Laffont et al. (2003, Proposition 2) derive a similar result but make an error. They do not check the second-order conditions. Doing so reveals that their first-order condition is neither necessary nor sufficient. Consequently, Laffont et al. do not identify possibilities (ii) and (iii). Case (ii) arises when the expected value of message exchange is distributed according to the negative exponential distribution.

18 Observe that the socially optimal prices depend only on the sum of the origination cost and the termination cost, so the assumption that the termination cost equals the origination cost is inconsequential.

19 There can be multiple values of $p^{*}$ and $r^{*}$ in some cases. What matters for our analysis, however, is $U^{*}+$ $V^{*}$, which is unique. 
the end-user coordination issue is solely whether end users purchase from their preferred network or stay out of the market entirely. For simplicity, we assume that end users can coordinate on Pareto-preferred continuation equilibria. Coordination implies that all end users will subscribe to a network if doing so would yield them positive surplus. Because the carrier can use the hookup fee to extract all of the surplus from its subscribers, the carrier prices to maximize the sum of its profits and the surplus enjoyed by its subscribers. This entails setting on-net prices at $p^{*}$ and $r^{*}$.

Next, consider the off-net prices that maximize the sum of a carrier's profits and its subscribers' consumer surplus derived from off-net traffic exchange. Given the separability of the sending and receiving programs and the fact that consumer surplus and profits are linear in the number of messages exchanged, these prices, denoted $p^{c}$ and $r^{c}$, are the solutions to:

and

$$
\max _{p} S(p)+(p-c-a) D(p)
$$

$$
\max _{r} S(r)+(r-c+a) D(r)
$$

Assuming that $0 \leq c-|a| \leq c+|a| \leq \sup \operatorname{supp} \psi(\cdot)$, the solution is readily shown to be $p^{c}=c+a$ and $r^{c}=c-a$.

In principle, there are potentially two roles for an access charge to play. One is to induce pricing below cost in order to internalize the effects of calling externalities. Unfortunately, access charges are not a good instrument for this purpose. In the equilibria just described, the access charge has no effect on the sum of off-net prices: $p_{i j}+r_{j i}=2 c$.

The fact that access charges cannot promote fully efficient pricing does not imply that they are irrelevant. In some cases, access charges can play a second role of inducing an efficient ratio of off-net send and receive prices even though their sum is too large. Proposition 2 of 
Hermalin and Katz (2004) characterizes the socially optimal retail prices when carriers' profits must be non-negative and hookup fees are infeasible. It parallels the present Proposition 1 in terms of when the send and receive prices are equal or at corners, but now the send and receive prices always sum to $2 c$. Applying this result, we obtain:

Proposition 2: Suppose the equilibrium in the market game entails both networks' setting off-net prices equal to $p^{c}$ and $r^{c}$. The socially optimal access charge depends on the hazard rate associated with density $\psi(\cdot)$ as follows:

(i) If the hazard rate is everywhere increasing, then $a=0$ is the unique socially optimal access charge.

(ii) If the hazard rate is constant, then any access charge that satisfies $-c \leq a \leq c$ is socially optimal.

(iii) If the hazard rate is everywhere decreasing, then there are two socially optimal access charges: $a=-c$ and $a=c .^{20}$

This result illustrates that it is a mistake to think of the originating carrier as purchasing termination services from the terminating carrier. Under the conditions of Proposition 2, whenever $a_{0}$ is optimal, so is $-a_{0}$. In other words, one could just as well think of the receiving carrier as purchasing origination services. This result also shows that, even in our highly symmetric model, an access charge of zero need not be optimal. DeGraba's (2003) finding that $a=0$ is socially optimal follows not from his assumption that senders and receivers have terminating a message differ, but these costs do not vary across carriers. In case (i), for example, the access charge is set equal to one half of the difference between the marginal cost of termination and the marginal cost of origination in order to induce equal send and receive retail prices. 
symmetric benefits overall, but from the much stronger assumption that there is symmetry on each specific message, which is almost certainly not satisfied in practice.

Now consider the privately optimal access charge. With otherwise homogeneous consumers, the two monopolists can use the hookup fee to extract fully any consumer surplus. Hence, the carriers have private incentives to set the access charge at the total surplus maximizing level given by Proposition 2.

Lastly, we briefly explore the effects of end-user beliefs that are in some ways the opposite of those that allow Pareto coordination. Suppose that each user believes that no other user will be on his or her preferred network unless such beliefs would lead to all users' subscribing at the prices offered. In this case, a carrier cannot set positive hookup fees and will set its prices to maximize transaction profits:

$$
\begin{aligned}
& p_{i j} \in \arg \max _{p} D(p)\{p-c-a\}, \\
& r_{i j} \in \arg \max _{p} D(r)\{r-c+a\},
\end{aligned}
$$

and

$$
p_{i i}, r_{i i} \in \arg \max _{p, r} D(p) D(r)\{p+r-2 c\} .
$$

On- and off-net prices will be inefficient, regardless of the access charge; $\min \left\{p_{i i}+r_{i i}, p_{i j}+r_{j i}\right\}>2 c$.

\section{COMPETITIVE EQUILIBRIUM WITH FULL PRICING FLEXIBILITY}

We now consider the opposite pole and examine the market equilibrium with undifferentiated Bertrand competitors. The presence of network effects gives rise to many equilibrium outcomes of the overall game. Proposition A1 in the Appendix fully characterizes the set of equilibria in which all end-users subscribe to a single carrier, and Proposition A2 offers 
a partial characterization of the set of symmetric equilibria in which both carriers attract subscribers. $^{21}$ The equilibria in the latter include those with and without off-net traffic.

One of the reasons that there is a large range of equilibria is that the following rational end-user strategies can have the effect of punishing a carrier that deviates from equilibrium: should a network deviate from the equilibrium prices, each user plays the strategy of subscribing to the non-deviating network unless he or she would enjoy strictly greater surplus from being the only subscriber on the deviating network. Another factor supporting the equilibria characterized in Proposition A2 is that "stealing” customers can be unprofitable when the on- and off-net prices are unequal and, hence one cannot apply the usual Bertrand undercutting argument. If a network tried to steal business by cutting its hookup fee, for example, it would lose money if it succeeded in attracting all end users but on-net traffic was less profitable than off-net traffic. Finally, note that, under both Propositions A1 and A2, there are positive-profit equilibria. As expected, the set of equilibrium outcomes is much smaller when consumers can coordinate on Pareto-preferred outcomes.

Proposition 3: Suppose end users coordinate on a Pareto-preferred continuation equilibrium, if one exists. Then the unique equilibrium outcome entails all end users' subscribing to a single network and their facing zero-profit, efficient prices $p_{i i}=p^{*}, r_{i i}=r^{*}$, and $h_{i}=h^{*} \equiv \frac{1}{2} D\left(p^{*}\right) D\left(r^{*}\right)\left\{p^{*}+r^{*}-2 c\right\} .^{22}$

With competitive carriers, the assumption that end users can coordinate on their Paretopreferred continuation equilibrium is strong, and one should be wary of drawing policy

\footnotetext{
21 Asymmetric equilibria also exist, but their characterization is rather involved.

22 The proofs of Propositions 2 and 4 can be found in the Appendix.
} 
conclusions based on it. One way of achieving this coordination, however, would be for a regulatory authority to hold a franchise auction for the right to be the monopoly provider. Policy makers may have other reasons for not adopting a system of monopoly franchises, but Proposition 3 identifies one benefit of such an approach.

We now consider the efficient choice of access charge. By Proposition A1, there exist equilibria in which both networks block off-net traffic by setting infinite off-net prices. For such cases, the access charge has no effect on the set of equilibrium outcomes. Similarly, with Pareto coordinating end users, the only equilibrium is efficient (Proposition 3) but entails no off-net traffic and, hence, access charges are again irrelevant.

Access charges could matter in equilibria with positive levels of off-net traffic. Proposition A2 establishes that there exist zero-profit equilibria with efficient on-net prices for outcomes with positive levels of off-net traffic. The next result, however, shows that access charges cannot induce fully efficient pricing in any such equilibrium. ${ }^{23}$

Proposition 4: There is no access charge level that can induce an equilibrium in which both networks have positive numbers of subscribers and charge efficient on-and off-net prices.

Proposition 4 is the immediate consequence of the following fact:

Lemma 1: Any equilibrium in which the two networks charge the same prices as one another and do not engage in network-based discrimination must entail setting the common send price at $p^{c}$, the common receive price at $r^{c}$, and the common hookup fee at 0. 
Proof: Suppose not. That is, consider an equilibrium with symmetric, non-discriminatory pricing for which the price vector differs from $\left(p^{c}, r^{c}, 0\right)$. Given that on- and off-net prices are the same and the networks charge the same prices as one another, there are no proprietary network effects. Hence, by the usual Bertrand reasoning, the hookup charge, $h$, must be set to yield each network zero profits because otherwise a network could profitably steal the entire market by lowering the hookup fee slightly while holding all other prices constant.

Now, consider the consequences if network $i$ deviated by offering send and receive prices $p^{c}$ and $r^{c}$, respectively, both on and off net, and a hookup fee of $\varepsilon>0$. By construction, for any $p$ and $r$ not equal to $p^{c}$ and $r^{c}$,

$$
S\left(p^{c}\right) D(r)+S\left(r^{c}\right) D(p)>S(p) D(r)+S(r) D(p)-2 h,
$$

where $h=-\frac{1}{2}(p+r-2 c) D(p) D(r)$. Hence, for $\varepsilon$ sufficiently small, a consumer would subscribe to network $i$ if he or she thought no one else would do so. This remains true even if there is a small proportion on $i$. Hence, in any continuation equilibrium, network $i$ must attract some customers. This fact implies that the deviation would be profitable for $i$ because the carrier would earn a positive profit of $\varepsilon$ per subscriber. $\quad$ QED

The finding that access charges fail to internalize cross-carrier external effects is a key difference from the findings of models such as DeGraba (2003) that assume that the senders and receivers share a fixed proportion of the total benefits of a message. In those models, the only role for access charges is to induce the efficient ratio of send and receive prices. Thus, it is possible to induce efficient pricing. That is not the case in a more general model.

23 In theory, access charges might induce an efficient outcome if they were set so high that they choked off off-net message exchange and induced an equilibrium in which all users subscribed to a single carrier that priced on-net exchange efficiently. 


\section{RESTRICTED PRICING}

In this section, we consider the effects of two restrictions on carrier pricing.

\section{A. Non-discrimination Case}

Suppose that a carrier is not allowed to discriminate between on-net and off-net messages. Such a policy might be imposed by regulators concerned that discrimination would lead to tipping or facilitate off-net prices that fail to capture external benefits.

The multiplicity of equilibria makes regime comparison difficult. Thus, it is helpful to restrict the sets of equilibrium outcomes in two ways. First, suppose that end users can coordinate on a Pareto-preferred continuation equilibrium, if one exists. By Proposition 3, Pareto coordination leads to an efficient, zero-profit equilibrium outcome when carriers can discriminate. But the logic used to prove Lemma 1 implies that no such equilibrium exists under a non-discrimination rule. ${ }^{24}$ Hence, such a rule harms consumers when they can coordinate their subscription decisions. The reason is that the inability to discriminate makes it impossible for a network to internalize two-sided benefits through its on-net pricing without inviting a form of free riding by the other network and its subscribers.

Next, drop the assumption that end users can Pareto coordinate, but focus on equilibria with symmetric pricing:

Proposition 5: Suppose that network-based discrimination is infeasible.

(i) Any allocation of end users between the two networks can be supported as an equilibrium in which both carriers charge a send price of $p^{c}$, a receive price of $r^{c}$, and a hookup fee of 0 . There are no other equilibria with symmetric pricing. 
(ii) If the hazard rate associated with $\psi(\cdot)$ is constant or everywhere increasing, thenassuming the equilibrium entails symmetric pricing — the socially optimal access charge is $a=0$ and the corresponding equilibrium prices maximize total surplus subject to the constraint that $p+r=2 c$.

Proposition A1 demonstrates that, when network-based discrimination is allowed, there exist equilibria in which the carriers earn positive profits. Proposition 5 illustrates the fact that a non-discrimination requirement removes the one source of market power for undifferentiated networks that can arise when users cannot coordinate their subscription decisions. For this reason, end users can benefit from a non-discrimination rule. For example, if $D(c) S(c)$ is greater than the monopoly per-capita profit given no hookup fee ( $\pi^{m}$ in Proposition A1), then there exist equilibria with discrimination for which consumer surplus is less than $D(c) S(c)$, the level under the equilibrium in Proposition 5. However, as already noted, a non-discrimination rule may harm end users because the tipping equilibrium in which the carrier with positive sales efficiently prices at $p^{*}, r^{*}$, and $h^{*}$ is eliminated by such a rule.

\section{B. A Single Two-Part Tariff for Each Network}

Suppose that network $i, i=1,2$ can set only a single message price, $q_{i}$, and a hookup fee, $h_{i}$. This type of pricing has been practiced by many wireless carriers. ${ }^{25}$ Under this pricing structure, subscription to network $i$ yields expected consumer surplus

$$
S\left(q_{i}\right)\left(\alpha_{i} D\left(q_{i}\right)+\left(1-\alpha_{i}\right) D\left(q_{j}\right)\right)-h_{i} .
$$

25 In the U.S., wireless carriers often set non-uniform price schedules containing a large number of "free” (on- and off-net, incoming and outgoing ) minutes. Once these minutes are exhausted, there is often only a single per-minute charge, regardless of whether a call is on or off net and the party is a sender or receiver. Other plans, however, have unlimited free on-net calling or free receiving.. 
Network $i$ 's profits per subscriber are

$$
D\left(q_{i}\right)\left(\alpha_{i} D\left(q_{i}\right)+\left(1-\alpha_{i}\right) D\left(q_{j}\right)\right)\left(q_{i}-c\right)+h_{i} .
$$

Observe that the access charge does not appear in this expression for profits because the traffic flows are always balanced: $\alpha_{i} \alpha_{j} D\left(q_{i}\right) D\left(q_{j}\right)$ messages originate on $i$ and terminate on $j$. Equally many messages originate on $j$ and terminate on $i$.

Proposition 6: Access charges are irrelevant when each network has a single message price.

Observe that this result depends heavily on the homogeneity of consumers. If there were customers with unbalanced traffic patterns (e.g., a user knew ex ante that she was more likely to send a message than to receive one), then a network might offer a two-part tariff that is particularly attractive to a beneficial selection of customers. ${ }^{26}$

\section{CROSS-CARRIER INTERNALIZATION MECHANSIMS}

We next consider two forms of more sophisticated interactions by the carriers: repeat play and delegated decision making. In each case, we find that there is an important sense in which the access charge is irrelevant.

\section{A. Repeat Play}

Suppose now that there are infinitely many periods and during each period the carriers set their prices and end users then make their subscription and message-exchange choices as above.

Proposition 7: Suppose that end users can coordinate on a Pareto-preferred stage-game continuation equilibrium, if one exists. With repeat play, the access charge level has no effect on the networks' ability to sustain the fully collusive symmetric outcome. 
Proof: Consider a grim-trigger strategy in which the punishment regime entails each network's setting efficient on-net prices, infinite off-net prices, and a hook-up fee that just breaks even. Then the punishment profits of both carriers are 0 , which clearly is the harshest feasible punishment given that each carrier has the option to shut down. Observe that the value of the access charge has no influence on the punishment strategies or the resulting profit levels.

The collusive transaction prices maximize total surplus and the carriers then use the hookup charge to appropriate the surplus. A carrier's most profitable deviation would be to lower the hookup fee by a small amount to attract all of the subscribers and thus double its profits. Both the collusive profits and the deviation profits are independent of the access charge level. The carriers can sustain the symmetric fully collusive outcome if and only if the perperiod interest rate is 100 percent or less. QED

\section{B. Interdependent Pricing Policies}

Return to the assumption that carriers set prices only once, but now suppose that the carriers engage in strategic delegation. That is, the carriers play a two-stage game. In the first stage, the two carriers simultaneously set contracts for their managers. Alternatively, these contracts can be viewed as commitments to pricing policies. In the second stage, the first-stage contract (policy) choices become common knowledge and each carrier sets its prices accordingly. Although we consider this type of strategic delegation with observable contracts to be somewhat artificial, it is widely employed in several different strands of economic literature, including oligopoly theory. ${ }^{27}$

\footnotetext{
26 See, for example, Hermalin and Katz (2001a).

$27 \quad$ For references to some of the articles using this setup, as well as a critique of the overall approach, see Katz (in press).
} 
The following result makes use of the logic underlying Theorem 1 in Katz (in press):

Proposition 8: Suppose that each carrier internally delegates its pricing decisions and can commit to an agency contract that can be contingent on the rival carrier's pricing policy. Given any pair of price vectors such that each network's net payoff is at least as large as its maximin level, there is a pair of contracts that support those actions as an equilibrium.

Proof: Consider a pair of agency contracts each of which specifies a punishment price vector and an agreement price vector as well as a rule that instructs (i.e., is a forcing contract) the agent to implement the agreement price vector if and only if the other carrier has adopted the parallel contract. Otherwise, the contract instructs the agent to implement the punishment price vector. Specifically, consider a contract in which the punishment price vector has efficient on-net prices, infinite off-net prices, and hook-up fees set to yield zero profit to the carrier if it attracts all users.

To see that the contracts can support any individually rational set of price quintuples as an equilibrium, suppose that consumers can coordinate on a Pareto-preferred continuation equilibrium, if any exist. Clearly, if one carrier implements the punishment price vector, the other carrier can at most break even. Hence, any pair of agreement price vectors that yield each carrier non-negative profits can be supported as an equilibrium outcome. QED

This last result is independent of the discount rate. Interdependent contracts yield a larger set of equilibria than does repeat play because there are no gains from cheating given the nature of the punishment-it is instantaneous.

Observe that the level of the access charge has no effect on profits in any symmetric outcome. Observe too, that industry profits would be maximized by setting all send prices equal to $p^{*}$, all receive prices equal to $r^{*}$, and then using the hookup fee to extract all of the surplus 
from end users. Because this outcome is the symmetric equilibrium that maximizes the carriers' profits, one might expect it to be focal.

\section{RELATIONSHIP TO THE LITERATURE}

Our paper is related to work on both access charges paid between telecommunications carriers and interchange fees paid between participants in an electronic payment network. We discuss each in turn.

\section{A. Intercarrier Compensation}

A small but growing number of papers have analyzed intercarrier compensation in settings with two-sided benefits. ${ }^{28}$ In contrast with the present model, all of these papers consider one-shot games without interdependent pricing policies. Atkinson and Barnekov (2000) conclude that each carrier should recover from its own subscribers all costs not incremental to interconnection itself. Critically, Atkinson and Barnekov assume that retail prices are independent of the interconnection pricing regime. In practice, however, interconnection costs represent either marginal message costs or fixed per-subscriber costs and thus can be expected to affect a carrier’s profit-maximizing retail prices. In all of the work summarized below, the level of access charges can affect retail prices.

This work uses one of two strategies to model end-user benefits. The first is that taken in the present paper: a sender and a receiver's relative valuations of a message can vary across messages. Hermalin and Katz (2001a) and Laffont et al. (2003) use this strategy and

28 In addition to the literature summarized below, Armstrong's (2002) insightful survey of the interconnection literature briefly addresses two-sided benefits in settings where all receivers benefit equally from all messages. 
characterize socially and privately optimal pricing and access charges. ${ }^{29}$ Laffont et al.’s (2003) central finding is that networks generally price as if their marginal costs were the off-net costs (the "off-net-cost pricing principle”). They also find that discrimination between on- and off-net pricing can lead to connectivity breakdowns. Both of these themes feature prominently in our analysis.

There are several differences between the present paper and Hermalin and Katz (2001a) and Laffont et al. (2003). Unlike the present paper, both earlier papers examine situations in which an end user knows if he or she is going to be a sender or a receiver when choosing a network, which affects the nature of competition. There are also differences in the pricing strategies considered. Hermalin and Katz do not allow for subscriber charges or hookup fees. In that setting, the central role for access charges is to induce access prices that (second-best) efficiently apportion the marginal cost of message exchange between the sender and receiver, accounting for pricing distortions due to carrier market power and possible effects on carrier investment incentives. ${ }^{30}$ In the present model, a central finding is that access charges differentially affect the level and ratio of transactions prices, and that intercarrier internalization mechanisms are needed to achieve efficient retail pricing. Laffont et al. (2003) consider the use of hookup fees but only when differential on- and off-net pricing is infeasible. They find that the only equilibrium role of hookup fees is to cover any per-subscriber connection cost; in their model, hookup fees are never used to subsidize below-cost on-net pricing. We also provide a more complete characterization of optimal retail prices in the symmetric-demand case (our

29 Laffont et al.’s (2003) analysis builds on their characterization of socially optimal retail prices. However, as noted in footnote 17 above, that characterization contains an error, which affects their analysis of socially optimal access charges. 
Proposition 1) than do the earlier papers, and we allow for other cross-carrier internalization mechanisms.

The second model of end-user benefits assumes that the sender benefits are a fixed proportion of the total benefits. Importantly, the assumption of constant proportional benefits implies that the first-best can be attained by setting send and receive prices that sum to marginal cost. As should be evident, there is no reason to believe that efficient pricing has this form in practice. Using this model, DeGraba’s (2003, p. 224) main findings are that, given enough assumptions about symmetry and functional forms: (a) an access charge equal to zero can induce efficient retail pricing; (b) setting the access charge equal to termination costs can lead to inefficiently little message exchange; and (c) setting the access charge equal to the termination cost can create a tipping effect. In contrast, we show that: (a) no level of the access charge can induce efficient retail prices with positive levels of off-net traffic, and equal send and receive prices may be non-optimal even when consumers have identical demands at the time of subscription and networks have identical, symmetric costs; (b) setting the access charge equal to the termination cost can be optimal in some otherwise symmetrical settings; and (c) when one assumes that consumers can coordinate on Pareto-preferred continuation equilibria (as DeGraba does), tipping arises from the ability to engage in network-based price discrimination, regardless of the level of access charges (our Proposition 3).

Jeon et al. (2004) and Berger (2004 and 2005) examine optimal prices and access charges in Hotelling models in which benefits are split in constant proportion between the sender and receiver. Three of Jeon et al.'s (2004, p. 108) four main findings are that: (a) send prices should

30 For a recent analysis of the effects of access charges on carrier investments in a market with one-sided benefits, see Valletti and Cambini (2005). 
be set below the marginal cost of a message and this outcome can be induced by setting the access charge below the cost of termination; (b) when network-based discrimination is not allowed, the access charge can be set to induce the efficient outcome; and (c) network-based discrimination creates strong incentives for networks to eliminate off-net message exchange even between equal networks. ${ }^{31}$ Similar to finding (c), we find that carriers have a tendency to reduce off-net traffic, although they do not necessarily eliminate it in equilibrium. But when we allow for non-proportional user benefits, we find that (a) and (b) no longer hold. Specifically, it often is efficient to have both send and receive prices below marginal cost and access charges cannot be used to induce the efficient outcome.

Berger (2004) assumes that both receive prices and the hookup fee must be set equal to 0 . He shows that a carrier will tend to set its off-net send price above $c+a$ in order to make the rival network less attractive because subscribers to the latter will receive fewer incoming messages. He also finds that carriers will use the access charge to facilitate collusion so that the privately optimal access charge will exceed the social optimum. These effects are tempered in our model by the use of hookup fee, and profit- and total-surplus-maximizing access charges can coincide.

Finally, Berger (2005) allows the networks to employ two-part tariffs but he does not permit the networks to charge receivers (i.e., $r_{i i} \equiv r_{i j} \equiv 0$ ). He finds that—subject to the restriction on receive prices—-that equilibrium send prices are socially optimal on net, but not off, because the network can recover 100 percent of the on-net efficiency gains through the hookup fee, but none of the off-net efficiency gains.

31 Their fourth main finding has to do with the role of receive prices and the value of regulating them. 


\section{B. Electronic Payment Networks and Interchange Rates}

Many electronic payment networks (e.g., the MasterCard and Visa credit and debit card networks) have requirements that a merchant's bank make a payment to a cardholder's bank when the cardholder makes a purchase at the merchant. These "interchange fees” are in important respects like intercarrier compensation and have been extensively studied. Leading recent analyses are Rochet and Tirole (2002), Schmalensee (2002), and Wright (2004).

There are also important institutional differences between communications and payments networks. An end user in the payments context knows whether it is a merchant or a consumer, while a given end user in our analysis may be on either side of the market. This fact has important implications for the nature of competition and the resulting equilibrium because an end user focuses solely on either the send or receive prices rather than both. For example, there is no result in the payments literature corresponding to Proposition 6.

Although there are important differences between telecommunications markets and payments networks, some of the fundamental conclusions are similar. First, in each case, the socially optimal retail prices depend on the sum of the two suppliers' marginal costs, not the specific costs incurred by the supplier on one side of the market or the other. Second, the payments literature emphasizes that interchange fees play a "balancing role" in recovering costs from the merchant and consumer sides of the market, rather than affecting the sum of the prices to the two sides. This perspective parallels the finding regarding the inability of the access charge to induce the socially optimal sum of send and receive prices. ${ }^{32}$

32 The size of the interchange fees (or an access fee) can affect the sum of prices when there are differential rates of pass through on the two sides of the market (see, e.g., Rochet and Tirole (2002) and Wright (2004), but these effects do not change the fundamental conclusion that interchange fees or access charges are highly imperfect instruments for achieving the right price level. 
The present paper can be seen as extending the analysis of interchange fees. For example, our analysis shows that the notion of balancing is potentially misleading. Specifically, when the hazard rate for expected transactions values is decreasing, it may be optimal to have one side of the market bear all of the costs even in an otherwise symmetrical situation. We also model hookup fees (e.g., annual fees for credit cards) and the possibility of differential pricing for off- and on-network transactions, the latter of which are known as "on-us” transactions in payment networks.

\section{CONCLUSION}

In the absence of receiver benefits, the receiver is unwilling to pay to exchange messages, the sender of a message can be viewed as the "cost causer," efficient pricing sets the send price equal to the marginal message cost, and the receiver's network should recover its message costs from the sender or the sender's carrier. The existence of receiver benefits fundamentally changes the analysis of interconnection charges. Instead of being how to recover the terminating network's costs from the sender, the issue is how to recover the combined marginal costs of a message between the sender and receiver in a way that efficiently internalizes the two-sided benefits. Such pricing generally entails both fixed and traffic-sensitive charges to both senders and receivers even when all costs are traffic sensitive.

The differences among the findings of the papers addressing interconnection with twosided benefits raises the following question: what are the enduring lessons from the literature to date? We close by conjecturing that the following six points will hold more generally:

- It is misleading to think of the originating carrier as purchasing termination services. One could just as well think of the terminating carrier as purchasing origination services. There are theoretical arguments for both positive and negative access charges. 
- There are two components to inducing efficient pricing. One is to set the ratio of send and receive prices correctly for a given total. The other is to set the sum correctly. In important cases, an access charge can help with the former but not the latter. Stated another way, there is a missing market (senders and receivers do not pay each other to communicate) for which the access charge cannot fully substitute.

- Even in highly symmetrical situations, an access charge of zero may not be socially optimal.

- In absence of repeat play or inter-dependent pricing strategies, off-net prices tend to be inefficient because efficient prices benefit the subscribers to rival networks.

- Repeat play or inter-dependent pricing strategies can provide a form of crosscarrier internalization.

- There are plausible settings in which the level of access charges is irrelevant. 


\section{APPENDIX}

Proof of Proposition 1: We first prove several lemmas that lead to the proof of the main result.

Lemma A1: $p=0=r$ is not a solution to the welfare-maximizing pricing problem.

Proof: By assumption, $M(0)-2 c<0 .^{33}$ QED

Lemma A2: If the hazard rate is everywhere increasing or everywhere decreasing, then any interior solution must be symmetric and there can be at most one such solution.

Proof: The first-order conditions for an interior solution are $M(p)+r-2 c=0$

and $M(r)+p-2 c=0$. Setting these expressions equal to one another and rearranging terms, an interior solution must satisfy $M(p)-p=M(r)-r$, which can be written as

$$
\frac{S(p)}{D(p)}=\frac{S(r)}{D(r)} .
$$

By Lemma A1 of Hermalin and Katz (2004), if the hazard rate is strictly monotonic, then $D(q) / S(q)$ is a strictly monotonic function of $q$, which implies $p=r$.

A symmetric interior solution must satisfy $M(p)+p=2 c$. The left-hand side of the equation is strictly increasing in $p$ (with a derivative bounded below by 1 ), while the right-hand side is constant. By assumption, $M(0)<2 c$. Hence, $M(p)+p=2 c$ has exactly one solution.

\section{QED}

Lemma A3: If the hazard rate is everywhere increasing, then there is a unique optimal price pair, $\left(p^{*}, r^{*}\right)$, and it satisfies $0<p^{*}=r^{*}<c$. 
Proof: Given the two lemmas above and the fact that efficient send and receive prices sum to less than $2 c$, we need only show that there cannot be a corner solution with one of the two prices equal to 0 . The proof proceeds by contradiction.

Suppose counterfactually that $p^{*}=0$. Then it would have to be the case that

$$
M\left(r^{*}\right)-2 c \geq 0 .
$$

Having an interior solution with respect to $r$ implies

$$
M(0)+r^{*}-2 c=0 .
$$

These two expressions can be simultaneously satisfied only if

$$
M\left(r^{*}\right)-r^{*} \geq M(0)-0 .
$$

But, applying the argument used in Lemma A2, this inequality cannot hold when the hazard rate is everywhere increasing. QED

Lemma A4: If the hazard rate is everywhere decreasing, then both $p^{*}=0, r^{*}=2 c-M(0)$ and $r^{*}=0, p^{*}=2 c-M(0)$ are efficient price pairs.

Proof: From the analysis above, we must show only that there cannot be a positive, symmetric solution. Suppose, counterfactually, that $p^{*}=q^{*}=r^{*}$ for some $q^{*}>0$. Consider increasing one price by $\Delta$ and decreasing the other by $\Delta$. The change in welfare is

$$
\begin{aligned}
& {\left[S\left(q^{*}-\Delta\right) D^{\prime}\left(q^{*}+\Delta\right)-S\left(q^{*}+\Delta\right) D^{\prime}\left(q^{*}-\Delta\right)\right]} \\
& +\left(2 c-2 q^{*}\right)\left[D\left(q^{*}-\Delta\right) D^{\prime}\left(q^{*}+\Delta\right)-D\left(q^{*}+\Delta\right) D^{\prime}\left(q^{*}-\Delta\right)\right]
\end{aligned}
$$

The first bracketed expression has the same sign as

$$
\frac{D^{\prime}\left(q^{*}+\Delta\right)}{S\left(q^{*}+\Delta\right)}-\frac{D^{\prime}\left(q^{*}-\Delta\right)}{S\left(q^{*}-\Delta\right)} .
$$


As shown in Hermalin and Katz (2004, proof of Proposition 2), a decreasing hazard rate implies that $D^{\prime}(q) / S(q)$ is increasing in $q$. Hence, the first bracketed expression is positive. The second bracketed expression has the same sign as

$$
\frac{D^{\prime}\left(q^{*}+\Delta\right)}{D\left(q^{*}+\Delta\right)}-\frac{D^{\prime}\left(q^{*}-\Delta\right)}{D\left(q^{*}-\Delta\right)} \text {. }
$$

A decreasing hazard rate implies that this difference is positive (the hazard rate is $\left.-D^{\prime}(q) / D(q)\right)$ and, hence, the second bracketed expression is also positive. Therefore, symmetric prices cannot be optimal. QED

Lastly, suppose that the hazard rate is constant. Then $\omega$ must have an exponential distribution, and $D(q)=e^{-q / \mu}$ for some constant, $\mu$. As shown in Hermalin and Katz (2004), any two prices that sum to the same amount, say $k$, give rise to the same level of user surplus. They also give rise to the same quantity exchanged and, thus, the same production costs and carrier revenues. ${ }^{34}$ It follows that total surplus depends solely on $k$. Setting $r=0$ and $p=k$, the first-order condition derived above determines the optimal value of $k: M(0)+k-2 c=0$. Proposition 1 follows.

Proposition A1: Consider an outcome with no off-net traffic under which network $i$ charges onnet prices $p_{i}$ and $r_{i}$, with hookup fee $h_{i}$ and attracts proportion $\alpha_{i}$ of subscribers. Label the networks so that $\alpha_{1} \geq \alpha_{2}$. The outcome can be supported as an equilibrium of the overall game if and only if:

(i) $\pi^{i} \equiv \frac{1}{2} D\left(p_{i}\right) D\left(r_{i}\right)\left[p_{i}+r_{i}-2 c\right]+h_{i} \geq 0$ if $\alpha_{i}>0$;

34 The quantity exchanged is $D(p) D(k-p)=e^{-p / \mu} e^{-(k-) p / \mu}=e^{-k / \mu}$. 
(ii) $\frac{1}{2}\left\{D\left(p_{j}\right) S\left(r_{j}\right)+S\left(p_{j}\right) D\left(r_{j}\right)\right\}-h_{j} \geq \pi^{m}-\alpha_{i} \pi^{i}$, where $\pi^{m}$ is the per-subscriber profit when the network serves the entire population, sets a hookup fee of 0 , and charges the profit-maximizing on-net prices; and

(iii) $\frac{1}{2} \alpha_{1}\left\{D\left(p_{1}\right) S\left(r_{1}\right)+S\left(p_{1}\right) D\left(r_{1}\right)\right\}-\delta_{1} h_{1} \geq \frac{1}{2} \alpha_{2}\left\{D\left(p_{2}\right) S\left(r_{2}\right)+S\left(p_{2}\right) D\left(r_{2}\right)\right\}-\delta_{2} h_{2} \geq 0$ where $\delta_{i}$ equals 0 if $\alpha_{i}$ equals 0 and 1 otherwise, and the first inequality holds as an equality if $\alpha_{1} \alpha_{2}>0$

Proof of Proposition A1: Consider the following strategy for each network: In addition to charging prices that meet the conditions set forth above, it also sets infinite off-net prices. If $\alpha_{2}=0$, assume network 2 charges the same prices as network 1 (as will be evident, given the strategies of the other players, doing so is a weak best response for 2).

Let consumers play either pure strategies so that $\alpha_{i}$ join carrier $i$ and the rest join carrier $j$ or they each mix with probability $\alpha_{i}$ of joining carrier $i$ and probability $1-\alpha_{i}$ of joining carrier $j$. Observe these are equivalent (all payoffs are linear in $\alpha_{1}$ and $\alpha_{2}$ ) and, given the prices charged by the carriers, best responses to the carriers’ strategies. Further assume that, should a carrier deviate from the above prices, each consumer plays the strategy that he or she signs with the non-deviating carrier unless he or she would enjoy strictly greater surplus even if he or she were the only person on the deviating carrier. Because the surplus from subscribing to a carrier, given no off-net traffic, is increasing in the number of people subscribing to that carrier, the assumed conditions insure that that this is a credible threat by the consumers.

Carrier 1 would earn strictly lower profit if it deviated in a way that attracted no customers and carrier 2 would earn weakly lower profit if it deviated in such a fashion. Given 
the users' strategies, the only feasibly profitable deviation by $i$ must have a negative hookup charge; specifically, the deviation hookup fee, $\tilde{h}$, must satisfy:

$$
-\tilde{h}>\frac{1}{2}\left(D\left(p_{j}\right) S\left(r_{j}\right)+S\left(p_{j}\right) D\left(r_{j}\right)\right)-h_{j} \cdot{ }^{35}
$$

The largest profit per subscriber that carrier $i$ can earn gross of the hookup fee is $\pi^{m}$. Hence, $2\left(\pi^{m}+\tilde{h}\right)$ is an upper bound on a deviating carrier's profit. But, by condition (ii), this is strictly worse than what carrier $i$ would have earned had it not deviated. QED

Proposition A2: Consider an outcome in which the two networks have equal market shares and both charge on-net prices $p_{n}$ and $r_{n}$, off-net prices $p_{f}$ and $r_{f}$, and hookup fee $h_{0}$. This outcome can be supported as an equilibrium if:

(i) each carrier's per-capita equilibrium profits, $\pi_{e}$, are non-negative; and

(ii) $h_{0} \leq \min \left\{U_{e}, U_{n}-\pi^{m}-\frac{1}{2} M(0)\left(D\left(p_{f}\right)+D\left(r_{f}\right)\right)+\frac{1}{2} \pi_{e}\right\}$, where $U_{e}$ is equilibrium percapita consumer surplus under the prices above with an even division of users between the networks and $U_{n} \equiv \frac{1}{2}\left\{D\left(p_{n}\right) S\left(r_{n}\right)+D\left(r_{n}\right) S\left(p_{n}\right)\right\} .{ }^{36}$

Proposition A2 is not vacuous. If $p_{n}$ and $r_{n}$ are sufficiently close to $p^{*}$ and $r^{*}$ and off-net prices are sufficiently large that $D\left(p_{f}\right)+D\left(r_{f}\right)$ is sufficiently small and a carrier does not suffer losses from off-net traffic, then

$$
V_{e}+U^{*}-\pi^{m} \geq \frac{1}{2} V^{*}+U^{*}-\pi^{m}>U^{*}+V^{*}-\pi^{m}>0
$$
could drop condition (ii) from the statement of the proposition and conclude the proof here. Observe that $p_{\mathrm{n}}+r_{\mathrm{n}} \leq 2 c$ if negative hookup fees are infeasible. 
When these inequalities hold, conditions (i) and (ii) can be satisfied simultaneously. Observe that, to insure that a carrier does not lose money on off-net message exchange, it cannot be the case that $p_{f}<p^{c}$ and $r_{f}<r^{c}$.

Proof of Proposition A2: Given condition (ii) and the symmetry of the prices, it is a best response for consumers to allocate themselves evenly between the carriers and, by condition (i), carriers at least break even. Assume that, should a carrier deviate from the candidate prices, each user plays the strategy that he or she subscribes to the non-deviating carrier unless he or she would enjoy strictly greater surplus on the deviating carrier even if he or she were the only subscriber to that carrier. Given the network effects, this is a rational end-user strategy. ${ }^{37}$

A deviation that attracts no customers is unprofitable. Given the end users' strategies, a deviation can attract subscribers in a continuation equilibrium only if

$$
U_{f}^{i}-\tilde{h}>U_{n}-h_{0},
$$

where $\tilde{h}$ is network $i$ 's hookup fee and $U_{f}^{i}$ is the surplus enjoyed by a user who subscribes to network $i$ when all other users subscribe to network $j$. Consider a deviation by network $i$ that attracts proportion $\alpha>0$ of the consumers. Its expected profit per subscriber is

$$
\begin{aligned}
V^{i}+\tilde{h} & <V^{i}+U_{f}^{i}+h_{0}-U_{n} \\
& \leq V^{i}+U_{f}^{i}-\pi^{m}-\frac{1}{2} M(0)\left(D\left(p_{f}\right)+D\left(r_{f}\right)\right)+\frac{1}{2} \pi_{e} \\
& \leq \frac{1}{2} \pi_{e},
\end{aligned}
$$

where the second inequality follows from condition (ii) and the third inequality follows because

$$
V^{i} \leq \pi^{m} \text { and } U_{f}^{i} \leq \frac{1}{2} M(0)\left(D\left(p_{f}\right)+D\left(r_{f}\right)\right) .
$$

$37 \quad$ We make this strong assumption because there is a sense in which it makes deviations costly and thus helps us identify a "large" set of possible equilibria. 
Given that the deviating firm's profit is no greater than $2\left(V^{i}+\tilde{h}\right)$, it follows that a profitable deviation does not exist. QED

Proof of Proposition 3: The proof is by contradiction; that is, we suppose that, in equilibrium, at least one carrier is charging prices other than those specified in the statement of the proposition.

First, we can readily rule out scenarios in which one or more carriers is carrying traffic and losing money.

Second, it cannot be that only one carrier is charging the specified prices: Pareto coordination implies that that carrier would be carrying all the business and, by continuity, it would be able to increase the hookup fee slightly without losing customers, a contradiction.

Third, suppose that carrier $j$ had no customers in equilibrium. Carrier $j$ would earn zero profit. Consider a deviation by $j$ such that it offered efficient on-net prices, infinite off-net prices, and a hook-up fee larger than $h^{*}$ by an arbitrarily small amount. Among the continuation equilibria of this game, the one that is Pareto superior is for all end users to join carrier $j$. But this means there is a profitable deviation by $j$, a contradiction.

Finally, consider a candidate equilibrium in which both carriers have positive sales. Define

$$
u_{n}^{i} \equiv \frac{1}{2}\left(D\left(p_{i i}\right) S\left(r_{i i}\right)+D\left(r_{i i}\right) S\left(p_{i i}\right)\right) \text { and } u_{f}^{i} \equiv \frac{1}{2}\left(D\left(p_{j i}\right) S\left(r_{i j}\right)+D\left(r_{j i}\right) S\left(p_{i j}\right)\right)
$$


to be the expected surplus on-net and off-net, respectively, for an end user on carrier $i$ under this equilibrium. End-user rationality implies that per-capita consumer surplus is the same on both carriers:

$$
\alpha u_{n}^{1}+(1-\alpha) u_{f}^{1}-h_{1}=(1-\alpha) u_{n}^{2}+\alpha u_{f}^{2}-h_{2}
$$

where $\alpha \in(0,1)$ is the proportion of users on carrier 1 . This last expression can be rewritten as

$$
\alpha\left(u_{n}^{1}-h_{1}\right)+(1-\alpha)\left(u_{f}^{1}-h_{1}\right)=(1-\alpha)\left(u_{n}^{2}-h_{2}\right)+\alpha\left(u_{f}^{2}-h_{2}\right) .
$$

Assume $u_{n}^{1}-h_{1} \leq u_{n}^{2}-h_{2}$ (because 1 and 2 are arbitrary, this is without loss of generality). Observe that all end users' subscribing to carrier 2 would be an equilibrium if

$$
u_{n}^{2}-h_{2}>u_{f}^{1}-h_{1}
$$

Moreover, this equilibrium would strictly Pareto dominate the “ $\alpha$-equilibrium” and thus the $\alpha$ equilibrium could not arise. Therefore, if the $\alpha$-equilibrium is played, then

$$
u_{n}^{2}-h_{2} \leq u_{f}^{1}-h_{1}
$$

By transitivity, $u_{f}^{1}-h_{1} \geq u_{n}^{1}-h_{1}$.

Define $\bar{\pi}=\alpha \pi_{1}+(1-\alpha) \pi_{2}$, where $\pi_{i}$ is carrier $i$ 's per-capita profit (inclusive of hookup fee). Suppose carrier 2 deviated by offering $p^{*}$ and $r^{*}$ on-net, infinite prices off-net, and a hookup fee equal to $-V^{*}+\bar{\pi}+\varepsilon, \varepsilon$ an arbitrarily small positive number. Observe that if all endusers joined carrier 2, then carrier 2's total profit would be

$$
2 \alpha \pi_{1}+2(1-\alpha) \pi_{2}+2 \varepsilon>2(1-\alpha) \pi_{2}
$$

Hence, for the $\alpha$-equilibrium to survive, this deviation cannot attract all end users; that is,

$$
u_{n}^{1}-h_{1} \geq U^{*}+V^{*}-\bar{\pi}
$$

Recalling that $u_{f}^{1}-h_{1} \geq u_{n}^{1}-h_{1}$, this last expression implies 


$$
\alpha u_{n}^{1}+(1-\alpha) u_{f}^{1}-h_{1}+\bar{\pi} \geq U^{*}+V^{*} .
$$

The left-hand side is the equilibrium per-capita sum of consumer surplus and profit. By the definitions of $U^{*}$ and $V^{*}$, this last expression can hold if and only if the on- and off-net send prices are $p^{*}$ and the on- and off-net receive prices are $r *$

We have shown that, if an equilibrium exists in which both carriers carry positive amounts of traffic, then it has to be efficient. But Proposition 4, which does not depend on this proposition, implies no such efficient equilibrium exists. Therefore, there is no equilibrium in which both networks carry positive traffic when end users Pareto coordinate.

To summarize, we have shown that it cannot be that both carriers have traffic unless the equilibrium is efficient; but, by Proposition 4, no such equilibrium exists. We have also shown that, if only one carrier carries traffic, then it must offer the prices specified in the proposition but it cannot be the only carrier to do so. As a last step, observe that if both carriers offer the specified on-net prices, both carriers set "high" off-net prices $\left(e . g ., D\left(p_{i j}\right)\right.$ and $D\left(r_{i j}\right)$ are near zero for $i \neq j$ ), and all end users sign with a single carrier, then there is no profitable deviation by either carrier. QED

Proof of Proposition 5: The logic used to prove Lemma 1 establishes that any equilibrium in which the two carriers charge the same prices must have a common send price of $p^{c}$, common receive price of $r^{c}$, and the common hookup fee of 0 .

An equilibrium at these prices exists for any allocation of users across the two carriers in which each user adopts the strategy of refusing to patronize a deviating carrier unless it offers strictly higher surplus under the assumption that there are no other subscribers to that carrier. In 
order to attract end users adopting this type of strategy, a deviating carrier must offer prices and a hookup fee such that

$$
\begin{aligned}
& \frac{1}{2}\left\{D(c+a) S\left(r_{f}\right)+D(c-a) S\left(p_{f}\right)\right\}-h \\
& \quad>\frac{1}{2}\{D(c+a) S(c-a)+D(c-a) S(c+a)\} .
\end{aligned}
$$

By the definition of $p^{c}$ and $r^{c}$,

$$
\begin{aligned}
\frac{1}{2} D(c+a) & \left\{S\left(r_{f}\right)+D\left(r_{f}\right)\left[r_{f}-c+a\right]\right\}+\frac{1}{2} D(c-a)\left\{S\left(p_{f}\right)+D\left(p_{f}\right)\left[p_{f}-c-a\right]\right\} \\
\leq & \frac{1}{2}\{D(c+a) S(c-a)+D(c-a) S(c+a)\} .
\end{aligned}
$$

Subtracting each side of inequality (2) from the respective side of inequality (3),

$$
\frac{1}{2}\left\{D(c+a) D\left(r_{f}\right)\left[r_{f}-c+a\right]+D(c-a) D\left(p_{f}\right)\left[p_{f}-c-a\right]\right\}+h<0 .
$$

Suppose the deviating carrier were to attract all end users. Then its per-capita profit would be

$$
\frac{1}{2}\left\{D\left(p_{f}\right) D\left(r_{f}\right)\left[r_{f}-c+a\right]+D\left(r_{f}\right) D\left(p_{f}\right)\left[p_{f}-c-a\right]\right\}+h .
$$

By Proposition 4 of Hermalin and Katz (2004), expression (5) is less than or equal to

$$
\frac{1}{2}\left\{D\left(q_{f}\right) D\left(q_{f}\right)\left[q_{f}-c+a\right]+D\left(q_{f}\right) D\left(q_{f}\right)\left[q_{f}-c-a\right]\right\}+h,
$$

where $q_{f}=\frac{1}{2}\left\{p_{f}+r_{f}\right\}$. Subtracting the left-hand side of (4) from (6) and substituting $a=0$ yields

$$
\left\{D\left(q_{f}\right)-D(c)\right\} D\left(q_{f}\right)\left[q_{f}-c\right] \leq 0,
$$

with strict inequality for any $q_{f} \neq c$. Hence, expression (5) is negative.

The deviator's actual profit in the continuation game would be a convex combination of the left-hand side of inequality (4) and expression (5), both of which are negative. There is no profitable deviation.

Lastly, the second-best efficiency of the equilibrium prices follows from Proposition 2 of Hermalin and Katz (2004). QED 


\section{REFERENCES}

Armstrong, Mark, “Network Interconnection in Telecommunications,” The Economic Journal, Vol. 108, No. 448. (May, 1998), pp. 545-564.

Armstrong, Mark, "The Theory of Access Pricing and Interconnection," in Handbook of Telecommunications Economics, Vol. 1, Martin E. Cave, Sumit K. Mujumdar, and Ingo Vogelsang, (Eds.), North-Holland: Amsterdam, 2002.

Atkinson, Jay M. and Christopher C. Barnekov, “A Competitively Neutral Approach to Network Interconnection,” December 2000. OPP Working Paper Series \#34, Federal Communications Commission.

Berger, Ulrich, "Access Charges in the Presence of Call Externalities," Contributions to Economic Analysis \& Policy, Vol. 3, No. 1, Article 21 (2004).

, “Bill-and-Keep vs. Cost-Based Access Pricing Revisited,” Economic Letters, Vol. 86 (2005), pp. 107-112.

Bolt, Wilko and Alexander F. Tieman, "Social Welfare and Cost Recovery in Two-sided Markets,” Unpublished manuscript, Research Division, De Nederlandsche Bank, 2005.

DeGraba, Patrick, "Efficient Intercarrier Compensation for Competing Networks when Customers Share the Value of a Call,” Journal of Economics \& Management Strategy, Vol. 12, No. 2 (Summer, 2003), pp. 207-230.

Dessein, Wouter, “Network Competition in Nonlinear Pricing,” The RAND Journal of Economics, Vol. 34 (2003), pp. 593-611.

Federal Communications Commission, Developing a Unified Intercarrier Compensation Regime, CC Docket No. 01-92, Further Notice of Proposed Rulemaking, FCC 05-33 (released March 3, 2005).

Hahn, Jong-Hee, "Network Competition and Interconnection with Heterogeneous Subscribers," International Journal of Industrial Organization, Vol. 22 (2004), pp. 611-631.

Hermalin, Benjamin E., and Michael L. Katz, "Network Interconnection with Two-Sided User Benefits,” unpublished manuscript, University of California, Berkeley, 2001a.

, "Retail Telecommunications Pricing in the Presence of External Effects," in Gary Madden, ed., International Handbook on Emerging Telecommunications Networks, Cheltenham,UK: Edward Elgar Publishing, 2001b. , "Sender or Receiver: Who Should Pay to Exchange an Electronic Message?” The RAND Journal of Economics, Vol. 35 (2004), pp. 423-448. "Intercarrier Compensation with All-You-Can-Eat Retail Pricing," unpublished manuscript, University of California, Berkeley, 2006. 
Jeon, Doh-Shin, Jean-Jacques Laffont, and Jean Tirole, “On the 'Receiver-Pays' Principle,” The RAND Journal of Economics, Vol. 35 (2004), pp. 85-110.

Katz, Michael L., “Observable Contracts as Commitments: Interdependent Contracts and Moral Hazard,” Journal of Economics \& Management Strategy, in press.

Laffont, Jean-Jacques, Scott Marcus, Patrick Rey, and Jean Tirole, “Internet Interconnection and the Off-Net-Cost Pricing Principle,” The RAND Journal of Economics, Vol. 34 (2003), pp. 370-390.

Laffont, Jean-Jacques, Patrick Rey, and Jean Tirole, "Network Competition: I. Overview and Nondiscriminatory Pricing” The RAND Journal of Economics, Vol. 29, No. 1. (Spring, 1998a), pp. 1-37.

Laffont, Jean-Jacques, Patrick Rey, and Jean Tirole, “Network Competition: II. Price Discrimination” The RAND Journal of Economics, Vol. 29, No. 1. (Spring, 1998b), pp. 38-56.

Laffont, Jean-Jacques, and Jean Tirole, Competition in Telecommunications, Cambridge : MIT Press, 2000.

Rochet, Jean-Charles, and Jean Tirole, "Cooperation among Competitors: Some Economics of Payment Card Associations,” RAND Journal of Economics, Vol. 33, No. 4 (Winter 2002), 549-570.

Schmalensee, Richard, "Payment Systems and Interchange Fees," The Journal of Industrial Economics, Vol. L, No. 2 ( 2002), pp. 103-122.

Taylor, Lester D., Telecommunications Demand in Theory and Practice, Dordrecht: Kluwer Academic Publishers,1994.

Valletti, Tommaso M., and Carlo Cambini, “Investments and Network Competition,” The RAND Journal of Economics, Vol. 36 (2005), pp.446-467.

Willig, Robert, “The Theory of Network Access Pricing," in Issues in Public Utility Regulation, ed. by H. Trebing. Michigan State University Press, East Lansing, MI. 1979.

Wright, Julian, “The Determinants of Optimal Interchange Fees in Payment Systems,” The Journal of Industrial Economics, Vol. LII, No. 1 (March 2004), pp. 1-26. 